\title{
Pediatric acute myeloid leukemia with complex karyotype involving $\mathrm{t}(8 ; \mathrm{I})(\mathrm{q} 22 ; \mathrm{q} \mid 3)$
}

\begin{abstract}
Chromosomal translocations involving high mobility group AT-hook 2 (HMGA2) gene at $12 \mathrm{q} 14$ has been detected in various malignancies, most notably lipoma. Although some cases of hematologic malignancies with reciprocal translocations involving 12q13-15 have been rarely described, acute myeloid leukemia (AML) with $t(8 ; 12)$ (q22;q13) has not been reported to date. Herein, we present a case of 14-year-old girl who was diagnosed as AML with variant $M L L$ translocation having $\mathrm{t}(8 ; 12)(\mathrm{q} 22 ; \mathrm{q} 13)$ as a part of complex karyotype. Although this case showed an aggressive clinical course, analysis of further cases are needed to evaluate the prognostic significance of this rare cytogenetic abnormality in AML.
\end{abstract}

Keywords: AML, t(8;12)(q22;q13), HMGA2, MLL
Volume 7 Issue 2 - 2019

\author{
Joowon Park \\ Department of Laboratory Medicine, Dankook University \\ Hospital, Korea
}

\author{
Correspondence: Joowon Park, Department of Laboratory \\ Medicine, Dankook University College of Medicine, San 16-5, \\ Anseo-dong, Cheonan 330-715, Korea, \\ Email joowon@dankook.ac.kr
}

Received: March 13, 2019| Published: March 19, 2019

\section{Introduction}

High mobility group AT-hook 2 (HMGA2) is a chromatinremodelling factor that alters chromatin architecture by binding to AT-rich regions of DNA. Without any intrinsic transcriptional activity, the translated protein promotes or inhibits the expression of its target genes by interacting with the transcriptional machinery, resulting in chromatin structure modification, which is thought to contribute to the transformation process. ${ }^{1,2} H M G A 2$ is expressed mainly during embryonic development and hardly detected in normal adult tissue. Over expression of HMGA2 is observed in various cancers notably lipoma, pleomorphic salivary adenoma, and uterine leiomyoma. ${ }^{3-5}$ They are the consequences of chromosomal translocations involving 12q13-15 where the HMGA2 gene is located. ${ }^{6}$ Although some cases of hematologic malignancies with reciprocal translocations harboring 12q13-15 have been rarely reported, acute myeloid leukemia (AML) with $\mathrm{t}(8 ; 12)(\mathrm{q} 22 ; \mathrm{q} 13)$ has not been described so far. Here, we report a case of $M L L$-rearranged pediatric AML with complex karyotype involving $\mathrm{t}(8 ; 12)(\mathrm{q} 22 ; \mathrm{q} 13)$.

\section{Case presentation}

A 14-year-old girl was admitted for neck pain and fever for 5 days. Physical examination revealed swelling of left neck. Her blood cell counts were as follows: WBC, $1.59 \times 10^{9} / \mathrm{L} ; \mathrm{Hb}, 6.7 \mathrm{~g} / \mathrm{dL}$; and platelet, $68 \times 10^{9} / \mathrm{L}$. Peripheral blood smear showed $4 \%$ of blasts. Bone marrow $(\mathrm{BM})$ aspirate showed increased blasts, counted up to $74 \%$ of all nucleated cells. The leukemic blasts showed medium to large-size, prominent nucleoli, relatively abundant basophilic cytoplasm with occasional azurophilic granules (Figure 1). BM biopsy showed hypercellularity with diffuse infiltration of blasts (Figure 2). The leukemic blasts were immunohistochemically reactive for myeloperoxidase (MPO) (Figure 3). Flow cytometric analysis showed leukemic cells positive for CD13, CD33, CD64, CD11c, HLA-DR, cMPO and CD7, and negative for CD34 and terminal deoxynucleotidyl transferase (TdT). A cytogenetic study revealed the following chromosome abnormalities: 46, XX, $\mathrm{t}(5 ; 11)(\mathrm{p} 12 \mathrm{p} 15.3 ; \mathrm{q} 13 \mathrm{q} 23), \quad \mathrm{t}(8 ; 12)(\mathrm{q} 22 ; \mathrm{q} 13), \quad \operatorname{add}(14)(\mathrm{p} 12),-17$, $+\operatorname{mar}[10] / 46, \mathrm{XX}[10]$ (Figure 4). In addition, interphase fluorescence in-situ hybridization (FISH) analysis using a MLL LSI dual color, break-apart probe demonstrated $76 \%$ of cells with break-apart signals (Figure 5). FISH study for EGR1/D5S23 showed normal pattern on interphase cells; however, one D5S23 (5p15.2) signal was observed at chromosome 11 on metaphase cells (not shown). These results could be suggestive of $t(5 ; 11)$ with four-break rearrangement, which correlate with chromosomal results. Recurrent gene rearrangements in acute leukemias by multiplex reverse transcriptase-polymerase chain reaction (RT-PCR) including major and minor $B C R / A B L 1$, $P M L / R A R A$, and RUNX1/RUNX1T1 genes was negative. FLT3-ITD, NPM1, and KIT mutation tests showed negative results. Based on above findings, the patient was diagnosed as having acute myeloid leukemia with variant $M L L$ translocation. Concurrent neck computed tomography (CT) scan revealed diffuse superficial and deep infection of left neck with bilateral cervical lymphadenopathy. Chemotherapy was scheduled, but withheld due to persisting high fever. On followup CT scan, abscess formation of left neck was suspected. Despite intensive antibiotic and supportive therapies, the patient succumbed due to septic shock 28 days after admission.

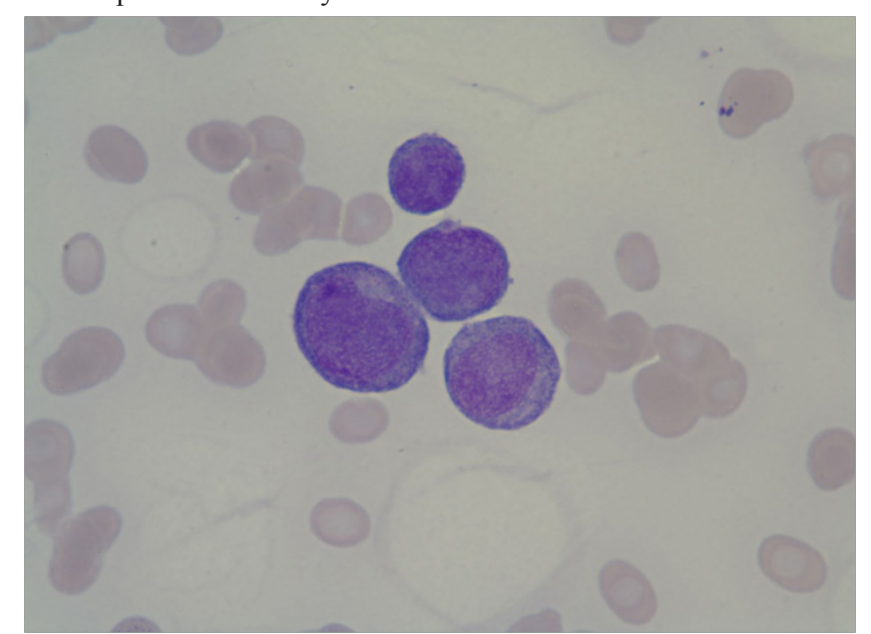

Figure I BM aspirate showing medium to large-sized blasts (Wright stain, $\times 1000$ ).

\section{Discussion}

Among the diverse chromosomal translocations in patients with hematologic malignancies, cases with chromosomal breakage at 12q13-q15 have been reported in a limited number, and only ten cases are found in the literature. Particularly, $\mathrm{t}(8 ; 12)(\mathrm{q} 22 ; \mathrm{q} 13)$ is much rarer, and there is only 1 case report of 53-year-old female with atypical chronic myeloid leukemia (CML), $B C R / A B L 1$-negative. Her 
BM karyotype showed $47, \mathrm{XXX}, \mathrm{t}(8 ; 12)(\mathrm{q} 22 ; \mathrm{q} 13) .{ }^{7}$ To the best of our knowledge, this is the first report to describe $t(8 ; 12)(\mathrm{q} 22 ; \mathrm{q} 13)$ in patient with AML. Unfortunately, we could not demonstrate HMGA2 rearrangement or expression by FISH or RT-PCR analyses due to insufficient specimen quality. However, according to previous studies of lymphoid and myeloid malignancies with translocations harboring 12q13-15, HMGA2 rearrangement was detected in all analyzed cases. ${ }^{7-10}$ Considering these results, we may assume that $12 \mathrm{q} 13$ translocation involved $H M G A 2$ in transforming event in this case. Further studies to understand the pathobiological mechanism in AML with 12q13-15 translocations are required.

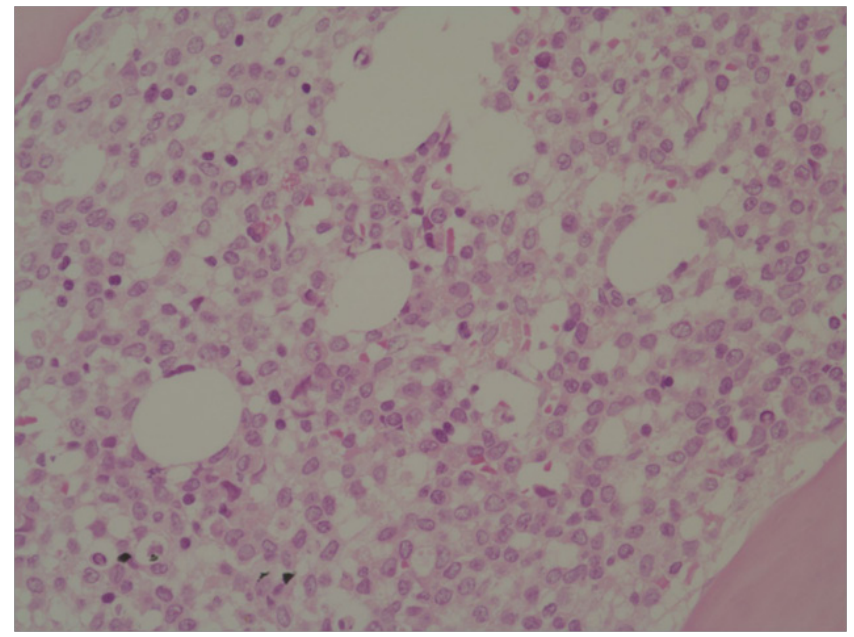

Figure 2 BM biopsy showing diffuse infiltration of blasts (H\&E stain, $\times 400$ ).

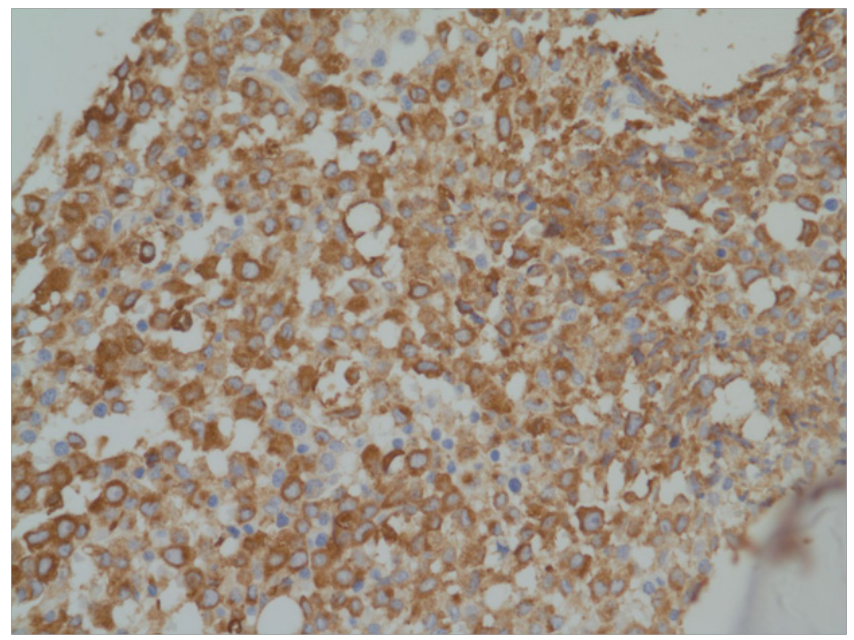

Figure 3 Blast cells with positivity for myeloperoxidase (MPO stain, $\times 400$ ).

The clinical outcomes of hematologic malignancies with reciprocal translocations involving 12q13-15 were variable. Among ten reported cases described above, four cases including the atypical CML case with $\mathrm{t}(8 ; 12)(\mathrm{q} 22 ; \mathrm{q} 13)$ were presented without clinical details. The other seven cases with 12q13-15 translocations including present case are summarized in Table 1. Among these seven cases, two cases showed stable clinical course (case 2 and case 5). Case 2 was a 33-year-old female with refractory anemia with excess blasts (RAEB)-1, and although the proportion of malignant cells in her BM karyotype increased to $100 \%$, she remained asymptomatic for 5years after presentation. ${ }^{7}$ Case 5 was a 67 -year-old female with myelodysplastic/myeloproliferative neoplasm, unclassifiable (MDS/ MPN-U). Notably, she had massive splenomegaly, pronounced basophilia and BM fibrosis at initial presentation. ${ }^{7}$ Due to limited information, the presence of additional molecular genetic anomalies of each case cannot be defined. Present case was accompanied by complex karyotype and variant $M L L$ translocation, both of which are generally associated with poor survival. It is reasonable to assume that these factors may partly contribute to a rapid progression of this case. Whether translocations involving 12q13-15 in AML has independently prognostic effect or not is uncertain at this point, mostly owing to a paucity of cases.

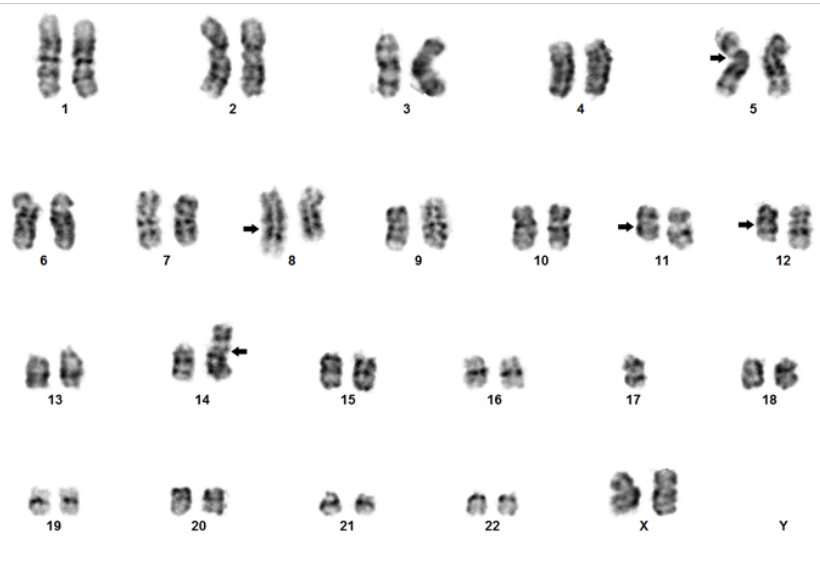

$\underset{\max }{t}$

Figure 4Cytogeneticanalysis showing 46,XX,t(5; II)(p|2p I5.3;q I $3 q 23), t(8 ; \mid 2)$ (q22; q 13),add(I4)(pI2),- 17,+mar[I0]karyotype.

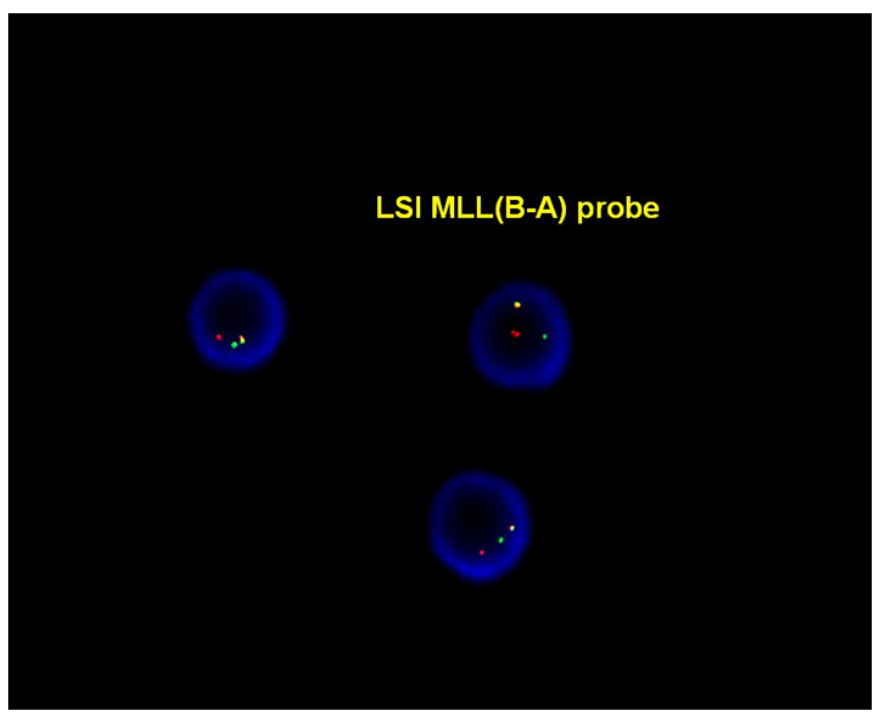

Figure 5 Interphase FISH demonstrating break-apart MLL signals.

In conclusion, we report the first case of pediatric AML having $\mathrm{t}(8 ; 12)(\mathrm{q} 22 ; \mathrm{q} 13)$ as a part of complex karyotype. The collection and analysis of further cases are required to determine the clinical significance and prognostic implication of this rare cytogenetic abnormality in AML. 
Table I Summary of reported cases with reciprocal translocations involving $12 q \mid 3-15$

\begin{tabular}{|c|c|c|c|c|c|}
\hline No & Age/Sex & Diagnosis & Karyotype & Clinical outcome & Reference \\
\hline Case 1 & $51 / \mathrm{F}$ & RT of CLL & $46, \mathrm{XX}, \mathrm{t}(12 ; 14)(\mathrm{q} 13 ; \mathrm{q} 32), \mathrm{t}(9 ; 13)(\mathrm{p} 13 ; \mathrm{q} 14)$ & Died 2 months after diagnosis & 8 \\
\hline Case 2 & $33 / \mathrm{F}$ & MDS (RAEB1) & $46, \mathrm{XX}, \mathrm{t}(7 ; 12)(\mathrm{p} 12 ; \mathrm{q} 13)[12] / 46, \mathrm{XX}[18]$ & Stable for 5 years & 7 \\
\hline Case 3 & $63 / \mathrm{M}$ & MDS (RAEB2) & $46, X Y, t(12 ; 14)(q 13 ; q 31)[6] / 46, X Y[24]$ & Died 6 months after diagnosis & 7 \\
\hline Case 4 & $72 / \mathrm{F}$ & MDS (RAEB1) & $46, X X, t(12 ; 12)(p 13 ; q 13)$ & Died 3 months after diagnosis & 7 \\
\hline Case 5 & $67 / \mathrm{F}$ & MDS/MPN-U & $46, \mathrm{XX}, \operatorname{add}(6)(\mathrm{p} 2 ? 2), \mathrm{t}(12 ; 20)(\mathrm{q} 15 ; \mathrm{q} 11.2)$ & Stable for 20 months & 7 \\
\hline Case 6 & $48 / \mathrm{F}$ & MDS (RAEB1) & $46, X X, t(11 ; 12)(q 23 ; q 15)[7] / 46, X Y[6]$ & Died 6 months after diagnosis & 7 \\
\hline $\begin{array}{l}\text { Present } \\
\text { case }\end{array}$ & $14 / \mathrm{F}$ & AML & $\begin{array}{l}\text { 46,XX,t(5;11)(p12p15.3;q13q23),t(8;12)(q22;q13),add(14) } \\
(\mathrm{p} 12),-17,+\operatorname{mar}[10] / 46, X X[10]\end{array}$ & Died 1 month after diagnosis & \\
\hline
\end{tabular}

RT, Richter transformation; CLL, chronic lymphocytic leukemia; MDS, myelodysplastic syndrome; RAEB, refractory anemia with excess blasts; MDS/MPN-U, myelodysplastic/myeloproliferative neoplasm, unclassifiable;AML, acute myeloid leukemia

\section{Acknowledgments}

None.

\section{Conflicts of interest}

The author declares that there is no conflicts of interest.

\section{References}

1. Cleynen I, Van de Ven WJ. The HMGA proteins: a myriad of functions (Review). Int J Oncol. 2008;32(2):289-305.

2. Wu Z, Eguchi-Ishimae M, Yagi $\mathrm{C}$, et al. HMGA2 as a potential molecular target in KMT2A-AFF1-positive infant acute lymphoblastic leukaemia. Br J Haematol. 2015;171(5):818-829.

3. Petit MM, Mols R, Schoenmakers EF, et al. LPP, the preferred fusion partner gene of HMGIC in lipomas, is a novel member of the LIM protein gene family. Genomics. 1996;36(1):118-129.

4. Zhou X, Benson KF, Przybysz K, et al. Genomic structure and expression of the murine HMGI-C gene. Nucleic Acids Res. 1996;24(20):40714077.
5. Geurts JM, Schoenmakers EF, Van de Ven WJ. Molecular characterization of a complex chromosomal rearrangement in apleomorphic salivary gland adenoma involving the 30-UTR of HMGIC. Cancer Genet Cytogenet. 1997;95(2):198-205.

6. Fedele M, Berlingieri MT, Scala S, et al. Truncated and chimeric HMGI-C genes induce neoplastic transformation of NIH3T3 murine fibroblasts. Oncogene. 1998;17(4):413-418.

7. Odero MD, Grand FH, Iqbal S, et al. Disruption and aberrant expression of HMGA2 as a consequence of diverse chromosomal translocations in myeloid malignancies. Leukemia. 2005;19(2):245-252.

8. Santulli B, Kazmierczak B, Napolitano R, et al. A 12q13 translocation involving the HMGI-C gene in richter transformation of a chronic lymphocytic leukemia. Cancer Genet Cytogenet. 2000;119(1):70-73.

9. Pierantoni GM, Santulli B, Caliendo I, et al. HMGA2 locus rearrangement in a case of acute lymphoblastic leukemia. Int J Oncol. 2003;23(2):363-367.

10. Andrieux J, Demory JL, Dupriez B, et al. Dysregulation and over expression of HMGA2 in myelofibrosis with myeloid metaplasia. Genes Chromosomes Cancer. 2004;39(1):82-87. 